Article

\title{
Tissue-Specific Analysis of Secondary Metabolites Creates a Reliable Morphological Criterion for Quality Grading of Polygoni Multiflori Radix
}

\author{
Li Liang, Jun Xu, Zhi-Tao Liang, Xiao-Ping Dong, Hu-Biao Chen (10) and Zhong-Zhen Zhao * \\ School of Chinese Medicine, Hong Kong Baptist University, Hong Kong, China; liangrb.ll@gmail.com (L.L.); \\ davidxujun@hkbu.edu.hk (J.X.); liangzhitao23@gmail.com (Z.-T.L.); dongxiaoping11@126.com (X.-P.D.); \\ hbchen@hkbu.edu.hk (H.-B.C.) \\ * Correspondence: zzzhao@hkbu.edu.hk; Tel.: +852-3411-2424
}

Received: 9 April 2018; Accepted: 6 May 2018; Published: 8 May 2018

\begin{abstract}
In commercial herbal markets, Polygoni Multiflori Radix (PMR, the tuberous roots of Polygonum multiflorum Thunb.), a commonly-used Chinese medicinal material, is divided into different grades based on morphological features of size and weight. While more weight and larger size command a higher price, there is no scientific data confirming that the more expensive roots are in fact of better quality. To assess the inherent quality of various grades and of various tissues in PMR and to find reliable morphological indicators of quality, a method combining laser microdissection (LMD) and ultra-performance liquid chromatography triple-quadrupole mass spectrometry (UPLC-QqQ-MS/MS) was applied. Twelve major chemical components were quantitatively determined in both whole material and different tissues of PMR. Determination of the whole material revealed that traditional commercial grades based on size and weight of PRM did not correspond to any significant differences in chemical content. Instead, tissue-specific analysis indicated that the morphological features could be linked with quality in a new way. That is, PMR with broader cork and phloem, as seen in a transverse section, were typically of better quality as these parts are where the bioactive components accumulate. The tissue-specific analysis of secondary metabolites creates a reliable morphological criterion for quality grading of PMR.
\end{abstract}

Keywords: Polygoni Multiflori Radix; laser microdissection; ultra-performance liquid chromatography triple-quadrupole mass spectrometry (UPLC-QqQ-MS/MS); secondary metabolites; quality grading

\section{Introduction}

Various specifications or grades of Chinese medicinal materials (CMMs) can be found in the market. The upper grade CMMs are supposed to be of better quality, thus justifying higher prices. Today, for determining grade and price, medicinal vendors mostly use morphological features, both external and internal (e.g., stem cross-sections), including shape, size (diameter, length), color, and texture [1]. Similarly, consumers primarily evaluate the quality of CMMs on the basis of morphological features in herbal markets. For each CMM, the particular characteristics used for grading were fixed centuries ago. However, modern research has found that the traditional interpretations of morphological features used for commercial grading of CMMs do not always reliably correspond to quality $[2,3]$. The accurate correspondence between quality and grading/price is an important issue both for the commercial markets and for clinical use of CMMs.

Today, chemical analysis has been applied to determine the content of active components in different commercial specifications and grades of herbal medicine. Until recently, in most of the research, an entire CMM or a whole plant was taken as the basis of research [4-6]. Today, with advanced 
technology, histochemical studies can extend to tissue-level analysis, and have shown that different tissues of CMMs contain different and distinct types of secondary metabolites [7-9]. At the gross, macroscopic level, the structure of different tissues creates morphological features, which is the external form of the CMMs. Thus the relationship between bioactive components and morphological features can be found by analyzing the distribution patterns of chemical components in different tissues. As a result, tissue- and cell-specific chemical profiling can link morphological features with secondary metabolites [10-12]. As such, both entire CMM sample and tissue-specific chemical profiling can be used to link morphological features and the quality of CMMs.

Recently, the technique of ultra-performance liquid chromatography triple-quadrupole mass spectrometry (UPLC-QqQ-MS/MS) has been used for precise quantitative analyses of the complex mixture of multi-components in CMMs with superior sensitivity and specificity [13-15]. In particular, multiple reaction monitoring (MRM) is a powerful quantitative mode operated on QqQ-MS/MS, in which two quadrupole mass analyzers are comprised and programmed at selective scanning, allowing only one ion pair (precursor and product ions) to be detected. Since two stages of mass selectivity are utilized, there is little interference from the background matrix [16,17]. In addition, laser microdissection (LMD) has been used as an accurate sampling tool for precise, contamination-free preparation of cell groups or single cells excised from histological tissue sections without adjoining tissues adhering. In addition, an accurate cutting area can be recorded, with the degree of preciseness up to $1 \mu \mathrm{m}^{2}$. [18,19]. A fluorescence light built inside the LMD unit enables each tissue or cell to appear with a specific fluorescence color according to its chemical constituents. This makes the border of each tissue more clear, enabling tissue or cell separation to be more accurate and specific [20]. The application of LMD and the UPLC-QqQ-MS/MS technique is proving to be a valuable technical platform for tissue- and cell-specific metabolite profiling of CMMs [21]. The method combining LMD and UPLC-QqQ-MS/MS can not only quantitatively analyze bioactive components of CMMs, but can also map the distribution patterns of bioactive components. Linking chemicals and morphological features of CMMs provides the scientific basis for their quality evaluation.

Polygoni Multiflori Radix (PMR, heshouwu in Chinese; derived from the tuberous roots of Polygonum multiflorum Thunb.) is widely used in traditional Chinese medicine. It is used to resolve toxin, moisten the intestines, and frees the stool [22]. Previous chemical analysis of PMR have found that it contains mainly three types of bioactive chemical ingredients: diphenyl ethylene, anthraquinones and polyphenols [23]. According to the Compendium of Materia Medica (Ben Cao Gang Mu), an ancient Chinese reference text, PMRs of a larger size are of better quality [24]. In the modern herbal market, based on our preliminary investigation in a local commercial herbal market, we found that PMR is sold in three grades according to their weight and size, with the price varying from 30 HKD (US\$4) per $\mathrm{kg}$ for smaller pieces to $150 \mathrm{HKD}$ (US\$20) per $\mathrm{kg}$ for the largest pieces. Wholesalers grade PMR according to weight: grade 1 represents tuberous roots more than $100 \mathrm{~g}$ in weight; grade 2, between $50 \mathrm{~g}$ to $100 \mathrm{~g}$ in weight; and grade 3, below $50 \mathrm{~g}$ in weight [25]. Commercial herb dealers chop the herb into smaller pieces and grade/sell it accordingly. While both sellers and buyers accept this grading, two questions arise: does the existing grading system accurately represent the quality of the herb? If not, is there another system, or are there other morphological criteria, that could be used to reliably represent quality?

We performed preliminary qualitative histochemical analysis of PMR by means of fluorescence microscopy and high performance liquid chromatography time-of-flight mass spectrometry (HPLC-TOF-MS). However, due to the limitations of tissue-separating technology at that time, the tissue parts were only roughly separated manually [26]. Because some types of specific tissues or cells of PMR are tiny, with a thickness even in units of $\mu \mathrm{m}$, and close together, they can be impossible to see and thus easily mis-cut manually; furthermore, the size of the cutting area is hard to measure, again due to its small size, and thus it is too inaccurate for quantitative study. Therefore, the analytes in the previous study were only qualitatively investigated without quantitative determination, which thus cannot reveal the histological distribution of chemicals in PMR. 
In this study, we conducted a quantitative, tissue-specific histochemical analysis of PMR by combining LMD and UPLC-QqQ-MS/MS. The objective of this study is to determine whether and how morphology corresponds to quality. To achieve this goal, we firstly determined the contents of 12 major chemicals in three different commercial grades of PMR raw materials by UPLC-QqQ-MS/MS to explore whether the existing grading system of PMR accurately represent the quality of the herb. The 12 analytes were trans-2,3,5,4'-tetrahydroxystilbene-2-O- $\beta$-D-glucopyranoside (trans-THSG), cis-THSG, emodin, physcion, emodin-8-O- $\beta$-D-glucosides and physcion-8-O- $\beta$-D-glucosides, gallic acid, proanthocyanidin B1, proanthocyanidin B2, epicatechin, catechin and epicatechin-3-gallate; these have been widely reported to be the major types and major bioactive chemical components in PMR [26-29] and thus were used as evidence of quality for this purpose. Then, we used a combination method of LMD and UPLC-QqQ-MS/MS to map the distribution patterns of these 12 analytes in six different PMR tissues, namely cork, cortex, phloem of abnormal vascular bundles, xylem of abnormal vascular bundles, phloem and xylem (Figure 1), in order to find out other morphological criteria for the quality grading of PMR. The results provide the chemical basis for quality evaluation of PMR, and expand the evaluation criteria to include internal morphological features.

A

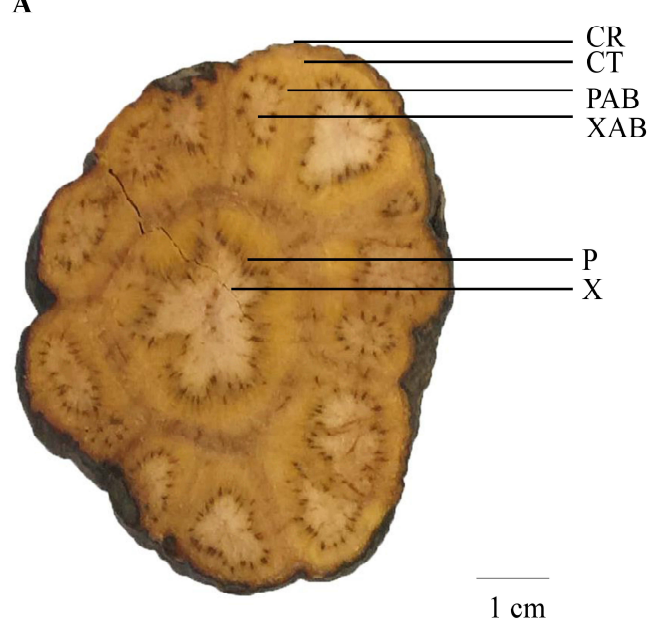

B

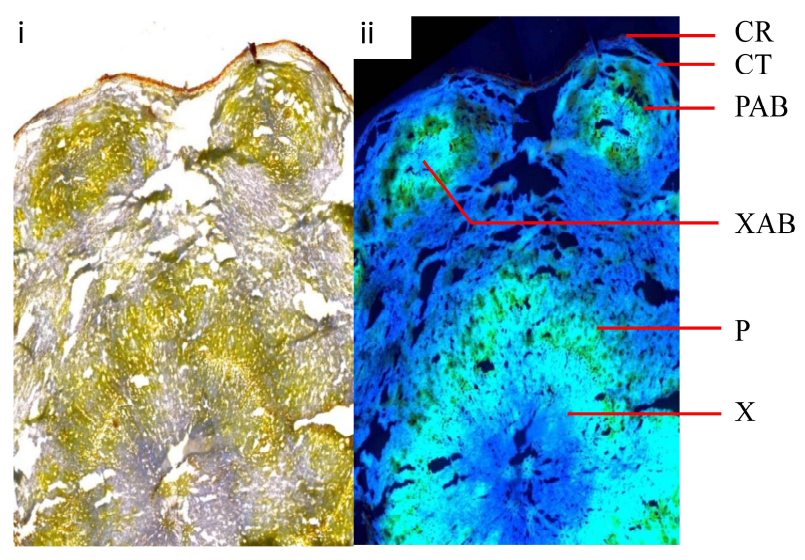

Figure 1. Transverse section of Polygoni Multiflori Radix (PMR) (PMR-TA1). (A) morphological features; (B) under microscope $(6.3 \times)$. (i) Under normal light microscope; (ii) under fluorescence mode. CR: cork; CT: cortex; PAB: phloem of abnormal vascular bundles; XAB: xylem of abnormal vascular bundles; P: phloem; X: xylem. 


\section{Results and Discussion}

\subsection{Sample Extraction}

Ultra-sonicated extraction conditions with regard to solvent (methanol, ethanol, 70\% methanol) and time (30 $\mathrm{min}, 45 \mathrm{~min}, 60 \mathrm{~min}$ ) were optimized according to the extraction efficiency of the total amount of the 12 analytes. For the extraction of experimental samples, the following conditions were chosen: $70 \%$ methanol was chosen as the solvent because it extracted a greater total of the 12 chemical components and because it gave better chromatographic resolution (Supplementary Materials Table S1). Two extractions were selected because two extractions yielded more than 95\% of the total 12 chemical components, which was deemed acceptable. In the extractions of micro-dissected tissues, $70 \%$ methanol was also used; however, the extremely tiny size of the micro-dissected tissue samples and the tiny amount of extraction solvent meant that errors in operation could easily occur. Thus, the micro-dissected tissues were extracted only once, with $100 \mu \mathrm{L} \mathrm{70 \%} \mathrm{methanol.} \mathrm{This} \mathrm{yielded} \mathrm{an} \mathrm{extraction}$ ratio greater than $90 \%$, which was also taken as acceptable.

\subsection{Optimization of Analytical Conditions}

In this study, UPLC-QqQ-MS/MS was used to explore the variation in content of the 12 major bioactive components between different grades and different tissues of PMR. In the optimization of UPLC-QqQ-MS/MS conditions, both negative and positive ion modes were tried, and negative ion mode was selected for its higher sensitivity (Supplementary Materials Table S1). The MRM fragments and collision voltage $(\mathrm{eV})$ of each analyte were individually optimized by Mass Hunter Optimizer Software (Aglient Technologies, Inc., Santa Clara, CA, USA, 2010, Version B.03.01) (Table 1). For example, the ions $[\mathrm{M}-\mathrm{H}]^{-} \mathrm{m} / z 243.1$ and $\mathrm{m} / \mathrm{z} 173.1$ of trans-THSG were observed under the MS condition of a $130 \mathrm{~V}$ fragmentor with the collision energy of $15 \mathrm{eV}$ and $39 \mathrm{eV}$, respectively. Since the ion of $\mathrm{m} / \mathrm{z} 243.1$ was more in abundant, it was selected as the precursor ion of trans-THSG. The ion pairs of the other 11 analytes were similarly optimized. The MS spectrums of the analytes are shown in Figure 2. Two UPLC columns, ACQUITY HSS T3 (100 mm $\times 2.1 \mathrm{~mm}, 1.8 \mu \mathrm{m})$ and ACQUITY BEH $(100 \mathrm{~mm} \times 2.1 \mathrm{~mm}, 1.7 \mu \mathrm{m})$ [20], together with different mobile phase compositions (methanol- $\mathrm{H}_{2} \mathrm{O} /$ acetonitrile- $\mathrm{H}_{2} \mathrm{O}$ with or without acidic additive) were tested. For 10 chemical components of the 12 analytes, including gallic acid, proanthocyanidin B1, proanthocyanidin B2, cis-THSG, trans-THSG, catechin, epicatechin, epicatechin-3-gallate, emodin-8-O- $\beta$-D-glucoside, physcion-8-O- $\beta$-D-glucoside, better chromatographic resolution was achieved by the ACQUITY HSS T3 column using water containing $0.1 \%(v / v)$ formic acid and $0.1 \%(v / v)$ acetonitrile-formic acid as the mobile phases; whereas for emodin and physicon, better chromatographic resolution was obtained by the ACQUITY BEH column using $3 \mathrm{mM}$ ammonium acetate in water and methanol. Based on the results, to provide suitable analytical conditions for all 12 analytes, two different conditions were used in this study.

\subsection{Method Validation}

As sample preparation procedures of raw material and tissue parts were different, the quantitative method was validated for both raw materials (PMR-RMA5) and micro-dissected tissues (PMR-TC2-5, PMR-TC3-6). As different tissues contain different chemical components, two tissue parts PMR-TC2-5 and PMR-TC3-6 were selected. For emodin-8-O- $\beta$-D-glucoside, physcion-8-O- $\beta$-D-glucoside, emodin, physcion, gallic acid and epicatechin-3-gallate, method validations were conducted on PMR-TC2-5; for the other six analytes, namely cis-THSG, trans-THSG, catechin, proanthocyanidin B1, proanthocyanidin B2, and epicatechin, method validations were conducted on PMR-TC3-6. 
Table 1. Multiple reaction monitoring (MRM) conditions in ultra-performance liquid chromatography triple-quadrupole mass spectrometry (UPLC-QqQ-MS/MS) analysis and method validation (linearity, limits of detection (LODs), limits of quantification (LOQs)) for quantitative determination of secondary metabolites.

\begin{tabular}{|c|c|c|c|c|c|c|c|}
\hline \multirow{2}{*}{ Analyte } & \multirow{2}{*}{ MRM } & \multirow{2}{*}{$\begin{array}{c}\text { Collision Voltage } \\
(\mathrm{eV})\end{array}$} & \multicolumn{3}{|c|}{ Calibration Curve } & \multicolumn{2}{|c|}{ Sensitivity (ng/mL) } \\
\hline & & & Range (ng/mL) & Equation & $\mathbf{R}^{2}$ & LODs & LOQs \\
\hline Gallic acid & $169.0 \rightarrow 125.0$ & 11 & $80-4000$ & $y=95.80 x-605.88$ & 0.9972 & 4.12 & 14.85 \\
\hline Proanthocyanidin B1 & $577.1 \rightarrow 407.0$ & 23 & $40-2000$ & $y=28.09 x-105.54$ & 0.9994 & 2.51 & 7.59 \\
\hline Catechin & $289.1 \rightarrow 245.1$ & 7 & 20-1000 & $y=25.33 x+256.56$ & 0.9974 & 17.95 & 48.25 \\
\hline Proanthocyanidin B2 & $577.1 \rightarrow 407.0$ & 23 & $40-2000$ & $y=25.93 x-48.90$ & 0.9991 & 3.17 & 15.92 \\
\hline Epicatechin & $289.1 \rightarrow 245.1$ & 7 & $10-1000$ & $y=31.33 x-78.60$ & 0.9939 & 15.52 & 40.66 \\
\hline cis-THSG & $405.0 \rightarrow 243.0$ & 15 & $5-1000$ & $y=213.54 x-348.14$ & 0.9948 & 1.04 & 1.62 \\
\hline Epcatechini-3-gallate & $441.1 \rightarrow 169.0$ & 15 & $5-1000$ & $y=55.85 x-82.32$ & 0.9936 & 0.99 & 6.62 \\
\hline trans-THSG & $405.0 \rightarrow 243.1$ & 15 & $40-8000$ & $y=196.23 x-357.59$ & 0.9992 & 9.64 & 11.02 \\
\hline Emodin-8-O- $\beta$-D-glucoside & $431.1 \rightarrow 269.1$ & 27 & $40-2000$ & $y=801.51 x+29.72$ & 0.9911 & 4.36 & 4.58 \\
\hline Physcion- $8-O-\beta$-D-glucoside & $445.1 \rightarrow 283.1$ & 7 & $40-2000$ & $y=58.92 x-103.32$ & 0.9929 & 4.84 & 7.14 \\
\hline Emodin & $269.0 \rightarrow 225.0$ & 25 & $80-800$ & $\mathrm{y}=2422.72+16798.78$ & 0.9907 & 0.22 & 1.15 \\
\hline Physcion & $283.0 \rightarrow 240.0$ & 20 & $40-2000$ & $y=117.20 x-1082.86$ & 0.9945 & 1.73 & 4.03 \\
\hline
\end{tabular}



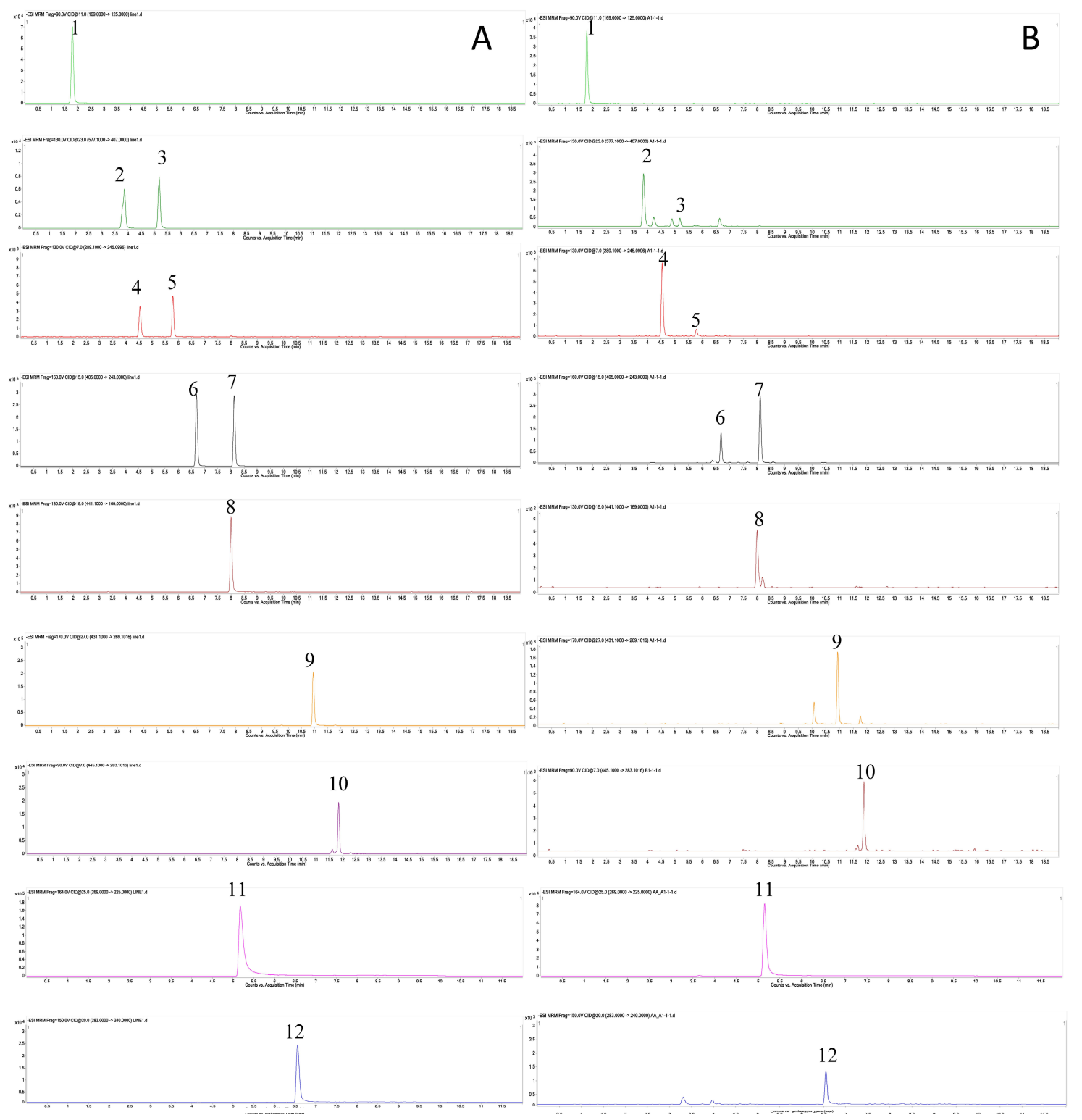

Figure 2. Mass spectrometry (MS) spectrums of 12 analytes with MRM mode. A: reference standard; B: sample (PMR-TA1). 1, gallic acid; 2, proanthocyanidin B1; 3, proanthocyanidin B2; 4, catechin; 5, epicatechin; 6 , cis-THSG; 7 , trans-THSG; 8, epicatechin-3-gallate; 9 , emodin-8-O- $\beta$-D-glucoside; 10 , physcion-8-O- $\beta$-D-glucoside; 11, Emodin; 12, Physcion.

The methods of validation, including tests of linearity, limits of detection (LODs), limits of quantification (LOQs) are summarized in Table 1; precision, repeatability, stability and recovery of raw materials and micro-dissected tissues are summarized in Tables 2 and 3, respectively. The results show good relationships between concentrations $\left(R^{2} \geq 0.9900\right)$. The LODs of all analytes are less than $17.95 \mathrm{ng} / \mathrm{mL}$, while the LOQs are less than $48.25 \mathrm{ng} / \mathrm{mL}$. The overall RSDs of intra-day and inter-day variations are not more than $7.48 \%$ and $9.84 \%$, respectively. The spike recoveries of raw materials range from $82.51 \%$ to $107.37 \%$, and the ranges of micro-dissected tissues are from $90.12 \%$ to $120.95 \%$. Taking trace determination and the extremely small size of the samples into consideration, recovery results are acceptable. The need for stability is satisfied because the RSDs are no more than $9.00 \%$ in $48 \mathrm{~h}$. All these results show that the established methods are accurate, sensitive, and precise for both raw materials and tissue-specific determination of all the 12 analytes in PMR. 
Table 2. Method validation (repeatability, precision, spike recovery and stability) for quantitative determination of secondary metabolites in raw materials of PMR.

\begin{tabular}{|c|c|c|c|c|c|c|c|c|c|c|}
\hline & \multirow{3}{*}{$\begin{array}{c}\text { Repeatability } \\
(n=6, \text { RSD, \%) }\end{array}$} & \multicolumn{4}{|c|}{ Precision $(n=6)$} & \multicolumn{3}{|c|}{ Spike Recovery ( $n=3$, Mean (RSD), \%) } & \multirow{2}{*}{\multicolumn{2}{|c|}{ Stability $(48 \mathrm{~h}, n=7)$}} \\
\hline & & \multicolumn{2}{|c|}{ Intra-day } & \multicolumn{2}{|c|}{ Inter-Day } & \multirow[b]{2}{*}{ Low } & \multirow[b]{2}{*}{ Middle } & \multirow[b]{2}{*}{ High } & & \\
\hline & & $\begin{array}{c}\text { Mean } \\
\text { (ng/mL) }\end{array}$ & RSD, \% & $\begin{array}{c}\text { Mean } \\
(\mathrm{ng} / \mathrm{mL})\end{array}$ & RSD, \% & & & & $\begin{array}{c}\text { Mean } \\
\text { (ng/mL) }\end{array}$ & RSD, \% \\
\hline Gallic acid & 10.81 & 394.15 & 3.01 & 471.86 & 7.69 & $96.71(4.58)$ & $97.23(4.15)$ & $94.94(1.53)$ & 445.58 & 8.73 \\
\hline Proanthocyanidin B1 & 7.43 & 959.60 & 2.47 & 999.00 & 4.08 & $90.73(6.29)$ & $91.72(5.46)$ & $90.85(4.85)$ & 1042.45 & 7.81 \\
\hline Catechin & 9.35 & 293.40 & 4.43 & 329.87 & 9.01 & $101.89(7.75)$ & $95.14(6.51)$ & $98.52(1.86)$ & 315.646 & 7.38 \\
\hline Proanthocyanidin B2 & 8.31 & 341.51 & 2.21 & 357.12 & 4.16 & $96.17(4.73)$ & $93.72(1.52)$ & $96.08(3.70)$ & 369.96 & 5.54 \\
\hline Epicatechin & 3.48 & 205.35 & 5.58 & 221.47 & 4.09 & $102.69(4.13)$ & 107.37(1.31) & $101.70(4.44)$ & 203.26 & 5.68 \\
\hline cis-THSG & 4.22 & 2012.47 & 1.21 & 2198.07 & 1.79 & $82.51(10.18)$ & $102.87(9.21)$ & $87.96(10.49)$ & 2107.79 & 4.76 \\
\hline Epcatechini-3-gallate & 7.27 & 440.67 & 7.25 & 448.75 & 5.69 & $103.50(5.13)$ & $95.52(8.18)$ & $100.89(2.06)$ & 456.16 & 4.23 \\
\hline trans-THSG & 2.42 & 7396.96 & 2.28 & 7932.62 & 6.72 & $95.15(6.80)$ & $92.82(5.34)$ & $85.98(8.56)$ & 7865.36 & 5.95 \\
\hline Emodin-8-O- $\beta$-D-glucoside & 3.19 & 2124.69 & 0.48 & 2365.74 & 0.78 & $94.72(1.47)$ & $100.49(1.99)$ & $97.93(1.58)$ & 2272.80 & 4.48 \\
\hline Physcion-8-O- $\beta$-D-glucoside & 3.58 & 503.18 & 1.54 & 558.48 & 1.59 & $94.11(2.09)$ & $95.36(4.40)$ & $85.81(0.38)$ & 529.89 & 4.66 \\
\hline Emodin & 2.02 & 719.23 & 8.32 & 669.05 & 9.95 & $99.05(2.92)$ & $106.78(2.56)$ & $101.18(2.33)$ & 682.54 & 5.77 \\
\hline Physcion & 3.40 & 605.38 & 4.49 & 569.70 & 6.19 & $97.94(9.05)$ & $92.87(6.61)$ & $99.27(8.78)$ & 578.33 & 3.97 \\
\hline
\end{tabular}

Table 3. Method validation (repeatability, precision, spike recovery and stability) for quantitative determination of secondary metabolites in micro-dissected tissues of PMR.

\begin{tabular}{|c|c|c|c|c|c|c|c|c|c|c|}
\hline & \multirow{3}{*}{$\begin{array}{c}\text { Repeatability } \\
(n=6, \text { RSD, \%) }\end{array}$} & \multicolumn{4}{|c|}{ Precision $(n=6)$} & \multicolumn{3}{|c|}{ Spike Recovery ( $n=3$, mean (RSD), \%) } & \multirow{2}{*}{\multicolumn{2}{|c|}{ Stability $(48 \mathrm{~h}, n=7)$}} \\
\hline & & \multicolumn{2}{|c|}{ Intra-Day } & \multicolumn{2}{|c|}{ Inter-day } & \multirow[b]{2}{*}{ Low } & \multirow[b]{2}{*}{ Middle } & \multirow[b]{2}{*}{ High } & & \\
\hline & & $\begin{array}{c}\text { Mean } \\
\text { (ng/mL) }\end{array}$ & RSD, \% & $\begin{array}{c}\text { Mean } \\
\text { (ng/mL) }\end{array}$ & RSD, \% & & & & $\begin{array}{c}\text { Mean } \\
\text { (ng/mL) }\end{array}$ & RSD, \% \\
\hline Gallic acid & 2.85 & 144.60 & 3.08 & 147.10 & 8.14 & $108.78(5.00)$ & $101.82(15.80)$ & $120.95(10.18)$ & 142.90 & 3.82 \\
\hline Proanthocyanidin B1 & 9.55 & 54.92 & 5.65 & 60.05 & 4.27 & 111.34(11.31) & $109.33(10.52)$ & $111.09(4.81)$ & 51.82 & 5.19 \\
\hline Catechin & 6.11 & 113.16 & 7.96 & 141.29 & 6.68 & 109.47(5.94) & $102.63(11.29)$ & $98.44(5.67)$ & 135.61 & 5.60 \\
\hline Proanthocyanidin B2 & 6.25 & 96.75 & 6.14 & 103.44 & 6.50 & 100.39(11.61) & $99.32(3.13)$ & $100.73(0.33)$ & 100.70 & 7.46 \\
\hline Epicatechin & 3.68 & 63.25 & 7.48 & 72.78 & 4.76 & $100.98(7.78)$ & $100.80(9.17)$ & $109.27(9.68)$ & 78.55 & 8.64 \\
\hline cis-THSG & 4.25 & 3040.38 & 2.09 & 3682.49 & 3.91 & 113.93(9.18) & 103.54(6.08) & $99.46(5.65)$ & 3378.57 & 5.82 \\
\hline Epcatechini-3-gallate & 6.33 & 162.27 & 6.03 & 178.00 & 4.79 & $93.66(8.48)$ & $97.62(6.72)$ & $90.98(10.54)$ & 131.54 & 4.90 \\
\hline trans-THSG & 5.91 & 4296.71 & 0.56 & 4921.06 & 5.25 & $109.77(6.74)$ & $112.86(4.00)$ & $102.28(9.76)$ & 7249.63 & 7.37 \\
\hline Emodin-8-O- $\beta$-D-glucoside & 4.92 & 193.50 & 2.44 & 241.92 & 3.34 & 113.83(1.50) & 109.74(15.73) & $101.83(2.13)$ & 359.83 & 6.05 \\
\hline Physcion-8-O- $\beta$-D-glucoside & 11.17 & 25.00 & 6.44 & 31.79 & 9.84 & 109.61(6.19) & $103.38(8.95)$ & $115.32(8.42)$ & 28.27 & 9.00 \\
\hline Emodin & 6.23 & 183.42 & 1.66 & 192.12 & 4.33 & $102.25(8.27)$ & $107.03(11.56)$ & $109.24(1.84)$ & 218.22 & 8.14 \\
\hline Physcion & 11.22 & 90.94 & 1.92 & 85.36 & 5.69 & $94.96(4.87)$ & $90.12(9.48)$ & $92.84(6.01)$ & 68.27 & 3.54 \\
\hline
\end{tabular}




\subsection{Quantitative Results and Discussion}

\subsubsection{Raw Materials}

Three major classes of chemicals, 12 compounds in total were quantitatively determined in raw materials of each grade of PMR samples, in order to explore the variation in major chemicals content of each grade and to find out whether there is a correlation between the existing grading system and the quality of the PMR. Sample extractions were first analyzed by UPLC-QqQ-MS/MS, and then one-way analysis of variance (ANOVA) statistical analysis was conducted by IBM SPSS Statistics 19.0 software (IBM, Armonk, NY, USA). The content of the 12 chemicals and variations are shown in Supplementary Materials Table S2 and Figure 3. In the statistical analysis, all $p$-values of the 12 analytes of each grade varied from 0.076 to 0.097 . Since a $p$-value below 0.05 is taken as a significant difference between targeted groups, the results of statistical analysis in this study indicated that there were no significant differences among the three grades in the contents of the 12 chemical components. In detail, there were only slightly differences in the content of two stilbene glucosides, namely trans-THSG and cis-THSG. For example, the average contents of trans-THSG in the first grade, second grade and third grade were $42,018.66 \pm 3115.35 \mu \mathrm{g} / \mathrm{g}$, $42,853.91 \pm 638.17 \mu \mathrm{g} / \mathrm{g}$ and $45,425.93 \pm 1600.70 \mu \mathrm{g} / \mathrm{g}$, respectively; and the $p$-value of three groups was 0.188 (>0.05). Similarly, the variations of the content of four anthraquinones, namely emodin, physcion, emodin-8-O- $\beta$-D-glucosides, physcion-8-O- $\beta$-D-glucosides, were only slight. For example, the average content of physcion was $414.95 \pm 158.59 \mu \mathrm{g} / \mathrm{g}$ (grade 1), $343.84 \pm 89.16 \mu \mathrm{g} / \mathrm{g}$ (grade 2) and $360.46 \pm 80.12 \mu \mathrm{g} / \mathrm{g}$ (grade 3 ), and the $p$-value was $0.741(>0.05)$. In the case of the six polyphenols, namely gallic acid, proanthocyanidin B1, proanthocyanidin B2, catechin, epicatechin, and epicatechin-3-gallate, the content of each grade also varied slightly. For example, the average content of catechin was $1559.21 \pm 249.69 \mu \mathrm{g} / \mathrm{g}, 1670.31 \pm 20.93 \mu \mathrm{g} / \mathrm{g}$ and $1995.95 \pm 172.68 \mu \mathrm{g} / \mathrm{g}$ in the sequence of first grade, second grade and third grade; and $p$-was $0.076(>0.05)$. Results revealed that PRM of different weights and sizes, which were recorded to be the basis for traditional quality grading [24,25], do not show any significant difference in chemical content. This fact suggests that the existing morphological criterion is unreliable for quality grading of PRM.

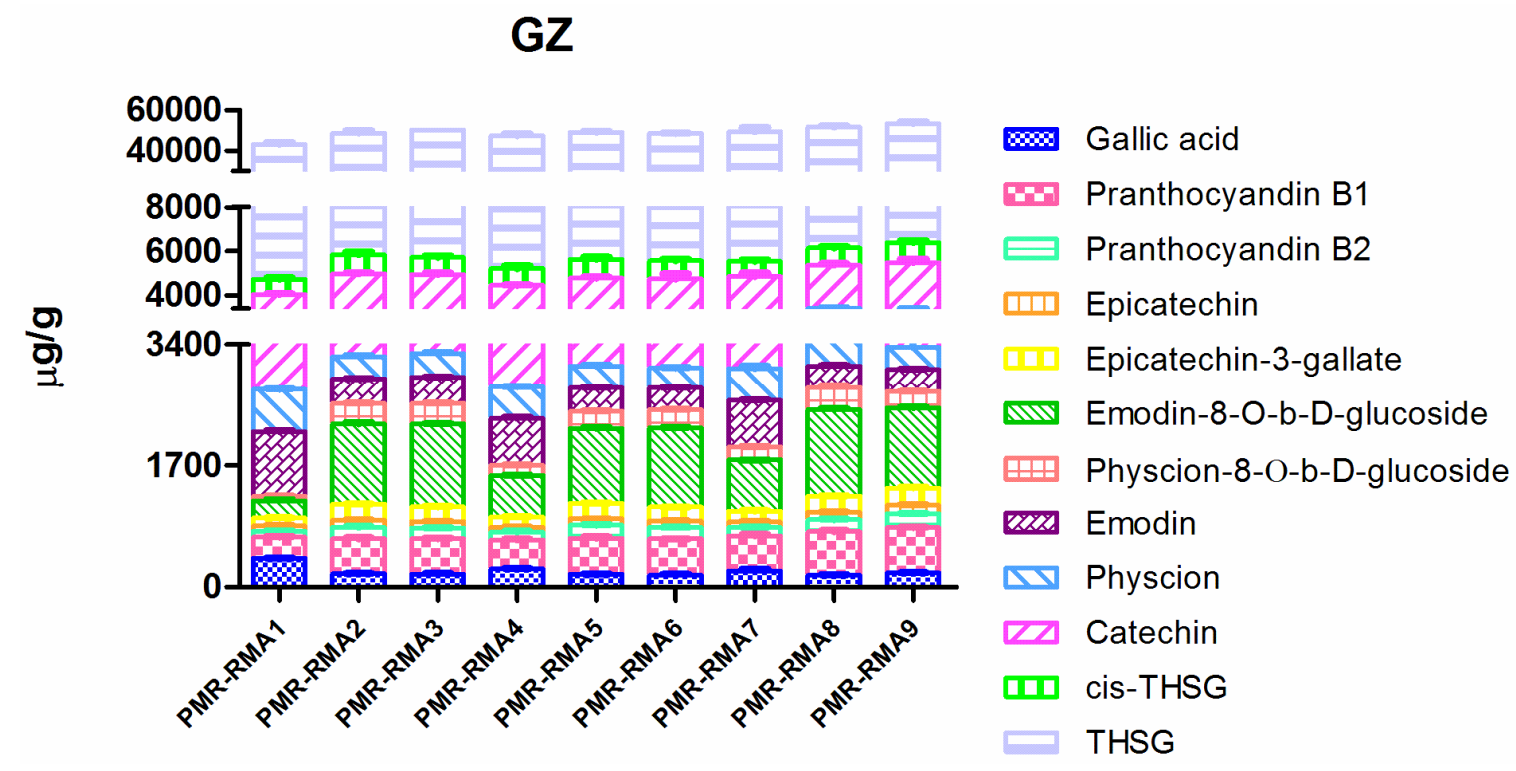

Figure 3. Content of the 12 analytes in raw material of Polygoni Multiflori Radix $(p>0.05)$. 


\subsubsection{Micro-Dissected Tissues}

In order to further explore how quality could be linked with morphological features, tissue-specific chemical profiling was further conducted by a combined method of LMD and UPLC-QqQ-MS. Twelve major chemical components were quantitatively determined in all tissues of PMR. The varied amount of each chemical compound in all tissues is listed in Supplementary Materials Table S3 and graphed in Figure 4.
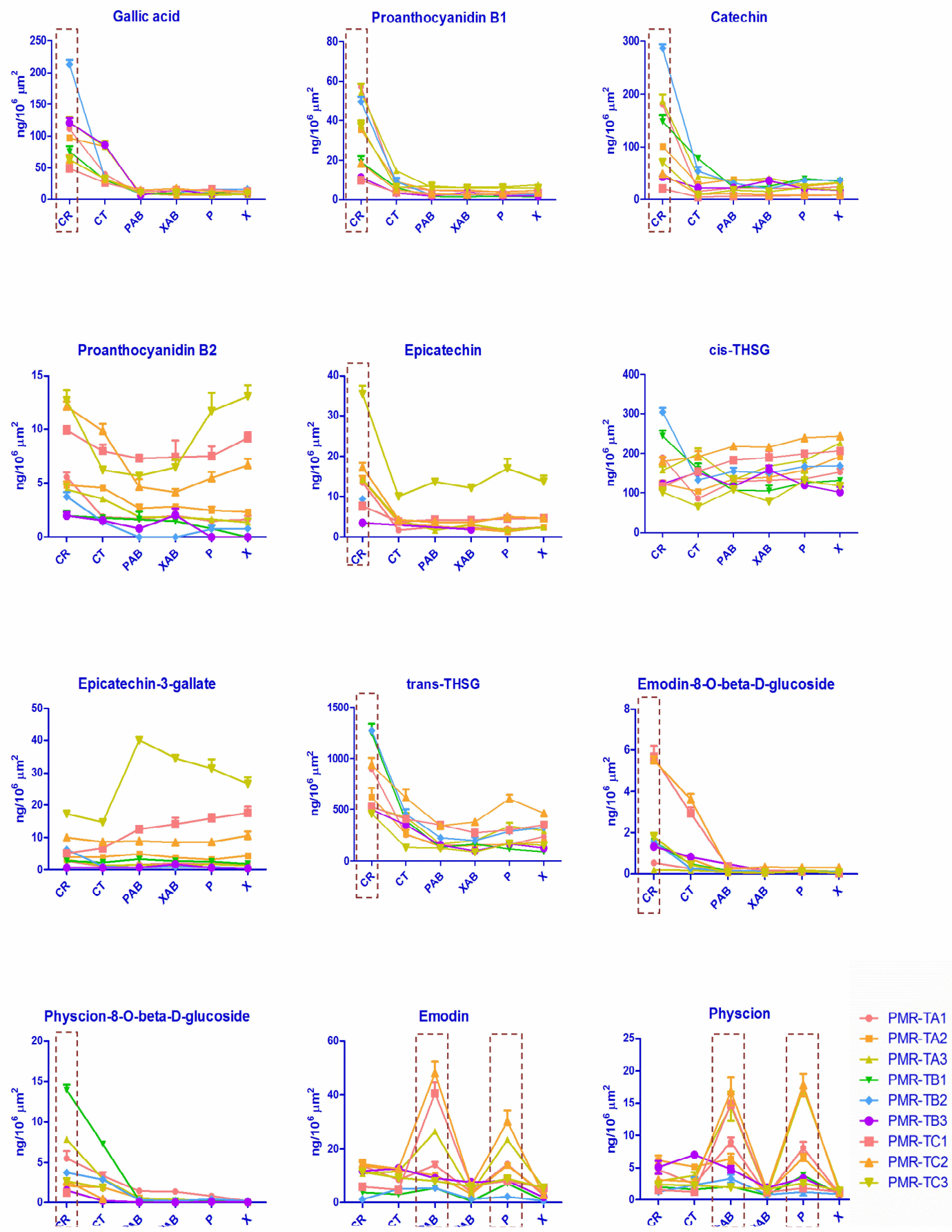

Figure 4. Variation in content of the 12 analytes in various tissues of PMR.

Results showed that the content of the 12 chemicals varied significantly in different tissues. For example, the content of trans-THSG of PMR-TA1 was $898.54 \pm 15.48 \mathrm{ng} / 10^{6} \mu \mathrm{m}^{2}$ in the 
cork; $255.06 \pm 7.05 \mathrm{ng} / 10^{6} \mu \mathrm{m}^{2}$ in the cortex; $154.51 \pm 8.81 \mathrm{ng} / 10^{6} \mu \mathrm{m}^{2}$ in the phloem of abnormal vascular bundles; $157.59 \pm 15.05 \mathrm{ng} / 10^{6} \mu \mathrm{m}^{2}$ in the xylem of abnormal vascular bundles; $163.41 \pm 21.24 \mathrm{ng} / 10^{6} \mu \mathrm{m}^{2}$ in the phloem; and $236.61 \pm 13.04 \mathrm{ng} / 10^{6} \mu \mathrm{m}^{2}$ in the xylem. In addition, the result of one-way ANOVA reveals that all $p$-values of the cork part were 0.00 $(<0.05)$, which means the content of trans-THSG is significantly different to those of other tissues. The results indicate that trans-THSG mainly accumulated in the cork. This result is the same as our previous findings in histochemical study of PMR [26]. The same distribution pattern was found for the polyphenols: gallic acid ( $p$-value 0.00), proanthocyanidin B1 ( $p$-value 0.00), catechin $(p$-value 0.00$)$, and epicatechin $(p$-value $\leq 0.019)$, and for the combined anthraquinones, namely emodin-8-O- $\beta$-D-glucosides $(p$-value $\leq 0.023$ ) and physcion-8-O- $\beta$-D-glucosides ( $p$-value 0.077 for cortex and $p$-value $\leq 0.01$ for the other tissues). Two free anthraquinones: emodin and physcion presented a different tendency and were found to be mainly distributed in the phloem and abnormal phloem. For example, the content of emodin was $14.49 \pm 1.39 \mathrm{ng} / 10^{6} \mu \mathrm{m}^{2}$, $12.70 \pm 0.89 \mathrm{ng} / 10^{6} \mu \mathrm{m}^{2}, 48.21 \pm 4.26 \mathrm{ng} / 10^{6} \mu \mathrm{m}^{2}, 6.38 \pm 0.82 \mathrm{ng} / 10^{6} \mu \mathrm{m}^{2}, 30.11 \pm 4.18 \mathrm{ng} / 10^{6} \mu \mathrm{m}^{2}$ and $2.97 \pm 0.08 \mathrm{ng} / 10^{6} \mu \mathrm{m}^{2}$ in the sequence of cork, cortex, phloem of abnormal vascular bundles, xylem of abnormal vascular bundles, phloem and xylem, respectively. Statistical analysis results have shown the $p$-value of physcion was no more than 0.038 and 0.006 in the phloem and abnormal phloem, respectively; and the $p$-value of emodin was no more than 0.022 in the abnormal phloem. This accumulated pattern differs from our previous findings, in which we proposed that the anthraquinones mainly exist in the cortex [26]. The inconsistency could be attributed to the limitations of tissue-separating technology at that time; tissues were separated manually and with adjoining tissues adhere, so tissues were easily mis-cut and, as a result, results were affected. In the case of the other three analytes: proanthocyanidin B2, epicatechin-3-gallate, and cis-THSG, the results of statistics analysis revealed that all $p$-values of these three analytes in different tissues were above 0.05 , which indicates there were no obvious distribution patterns of these three chemical compounds. The results indicate that stilbene glucosides, combined anthraquinones and polyphenols were mainly accumulated in the cork; free anthraquinones mainly existed in the phloem, and thus the cork and phloem should be of more medicinal value than other tissues. The tissue-specific analysis of secondary metabolites creates a new morphological criterion for quality grading of PMR. That is, PMR with broader cork and phloem, as seen in a transverse section, were typically of better quality as these parts are where the bioactive components accumulate.

\section{Materials and Methods}

\subsection{Plant Materials, Chemicals and Reagents}

The PMR materials were collected from three different habitats in China, and three replicate sample materials were from different biological plants (Table 4). All samples were authenticated as the tuberous roots of Polygonum multiflorum Thunb. by Prof. Zhong-Zhen Zhao from the School of Chinese Medicine, Hong Kong Baptist University. Voucher specimens were deposited in the Bank of China (Hong Kong) Chinese Medicines Centre of Hong Kong Baptist University.

Chemical standards for trans-THSG, emodin, physcion, catechin, proanthocyanidin B1, proanthocyanidin B2, and gallic acid were purchased from Chengdu Must Bio-Technology Co., Ltd. (Chengdu, China); standards for cis-THSG, epicatechin, epicatechin-3-gallate, emodin-8-O- $\beta$-D-glucoside, and physcion-8-O- $\beta$-D-glucoside were purchased from Chengdu Xunchen Biological Technology Co., Ltd. (Chengdu, China). HPLC-grade methanol and acetonitrile (E. Merck, Darmstadt, Germany), ammonium acetate (Sigma-Aldrich, St. Louis, MO, USA), HPLC grade formic acid (Tedia, Fairfield, OH, USA) were purchased. Ultra-pure water was prepared by a Mili-Q water purification system (Millipore, Burlington, MA, USA). 
Table 4. Sample information of PMR.

\begin{tabular}{ccccc}
\hline Sample No. & Grade & Type $^{(a)}$ & Cultivated Location & Collection Date \\
\hline PMR-RMA1 & $1^{(b)}$ & RM & Guizhou Province, Shibing Country & $2017-1-18$ \\
PMR-RMA2 & 1 & RM & Guizhou Province, Shibing Country & $2017-1-16$ \\
PMR-RMA3 & 1 & RM & Guizhou Province, Shibing Country & $2017-2-18$ \\
PMR-RMA4 & 2 & RM & Guizhou Province, Shibing Country & $2017-1-18$ \\
PMR-RMA5 & 2 & RM & Guizhou Province, Shibing Country & $2017-2-16$ \\
PMR-RMA6 & 2 & RM & Guizhou Province, Shibing Country & $2017-2-18$ \\
PMR-RMA7 & 3 & RM & Guizhou Province, Shibing Country & $2017-1-18$ \\
PMR-RMA8 & 3 & RM & Guizhou Province, Shibing Country & $2017-2-16$ \\
PMR-RMA9 & 3 & RM & Guizhou Province, Shibing Country & $2017-2-18$ \\
PMR-TA1 & 1 & T & Guizhou Province, Shibing Country & $2017-2-16$ \\
PMR-TA2 & 2 & T & Guizhou Province, Shibing Country & $2017-2-16$ \\
PMR-TA3 & 3 & T & Guizhou Province, Shibing Country & $2017-2-16$ \\
PMR-TB1 & 1 & T & Guangdong Province, Xinxing Country & $2017-2-8$ \\
PMR-TB2 & 2 & T & Guangdong Province, Xinxing Country & $2017-2-8$ \\
PMR-TB3 & 3 & T & Guangdong Province, Xinxing Country & $2017-2-8$ \\
PMR-TC1 & 1 & T & Hubei Province, Lizhou City & $2017-1-16$ \\
PMR-TC2 & 2 & T & Hubei Province, Lizhou City & $2017-1-16$ \\
PMR-TC3 & 3 & T & Hubei Province, Lizhou City & $2017-1-16$ \\
\hline
\end{tabular}

(a) RM: sample used for raw material analysis; T: used for micro-dissected tissue analysis; all samples were 1 year cultivated ones; (b) Grade 1: >100 g; grade 2: 50-100 g; grade 3: <50 g.

\subsection{Sample Preparation}

\subsubsection{Raw Material Extraction}

Raw materials were powdered, and each powdered sample of $0.1 \mathrm{~g}$ (accurately weighed) was ultra-sonicated with $20 \mathrm{~mL} 70 \%$ methanol for $45 \mathrm{~min}$ at $60^{\circ} \mathrm{C}$. Each solution was then centrifuged at $3000 \mathrm{rpm}$ for $10 \mathrm{~min}$. The supernatant was saved, and the residue was again extracted, and the supernatant saved. Then the residue was washed with $5 \mathrm{~mL} 70 \%$ methanol. The two supernatants and this solution were combined, made up to $50 \mathrm{~mL}$ with $70 \%$ methanol, and finally filtered through a $0.22 \mu \mathrm{m}$ filter for quantitative analysis.

\subsubsection{Tissue Extraction}

\section{Laser Microdissection}

PMR samples were first softened by wrapping with ultra-pure water-soaked non-cellulose paper, and then cut into small sections. Each section were then embedded in tissue-freezing medium (Thermo Shandon Limited, Runcorn, UK), and placed on a cutting platform in the cryostat (Thermo Shandon As620 Cryotome, UK) at $-20{ }^{\circ} \mathrm{C}$. Serial slices of $35 \mu \mathrm{m}$ thickness were cut at $-20{ }^{\circ} \mathrm{C}$ and directly moved on to a non-fluorescent positron-emission tomography (PET) microscope steel frame slide (76 $\mathrm{mm} \times 26 \mathrm{~mm}, 4 \mu \mathrm{m}$ thick, Leica, Wetzlar, Germany).

The slides were observed in fluorescence mode using a Leica microscope (Leica LMD 7000 system, Leica, Ben-shein, Germany). Laser microdissection was operated by a diode-pumped solid state (DPSS) laser beam at a speed of 1, aperture of 3, under a Leica LMD-BGR fluorescence filter system consisting of red light (excitation filter), blue light (suppression filter), green light (dichromatic mirror), with intensity of 50\%, at $10 \times$ magnification. Six tissues, namely the cork, cortex, phloem of abnormal vascular bundles, xylem of abnormal vascular bundles, phloem and xylem were dissected under fluorescence inspection mode, within an area of approximately $1.5 \times 10^{6} \mu \mathrm{m}^{2}$. The micro-dissected tissues were collected into caps of $500 \mu \mathrm{L}$ microcentrifuge tubes (Leica, Germany). 
Micro-Dissected Tissue Extraction

The micro-dissected tissue in each cap was transferred to the bottom of a microcentrifuge tube by centrifugation (Centrifuge 5415R, Eppendorf, Hamburg, Germany) at 10,000 rpm for 5 min, and then was ultra-sonicated with $100 \mu \mathrm{L} 70 \%$ methanol for $60 \mathrm{~min}$, at $60{ }^{\circ} \mathrm{C}$. Then the microcentrifuge tubes were centrifuged again for $10 \mathrm{~min}$ at $10,000 \mathrm{rpm} .90 \mu \mathrm{L}$ of each supernatant was transferred to a glass insert with a plastic bottom spring ( $400 \mu \mathrm{L}$, Grace, Hong Kong, China) in a $1.5 \mathrm{~mL}$ brown HPLC vial (Grace, Hong Kong, China) and stored at $4{ }^{\circ} \mathrm{C}$ for quantitative analysis.

\subsection{Ultra-Performance Liquid Chromatography Triple-Quadrupole Mass Spectrometry (UPLC-QqQ-MS/MS Analysis)}

\subsubsection{Conditions}

The quantitative analysis was conducted on an Agilent 6460 UHPLC-QqQ-MS/MS (Agilent Technologies, Santa Clara, CA, USA) with ESI ion source in negative mode. The chromatographic separations were acquired under two different conditions: (1) A UPLC T3 analytical column $(2.1 \mathrm{~mm} \times 100 \mathrm{~mm}$, I.D. $1.8 \mu \mathrm{m}$, ACQUITY UPLC HSS, Waters, USA) coupled with a T3 pre-column $\left(2.1 \mathrm{~mm} \times 5 \mathrm{~mm}\right.$, I.D.1.8 $\mu \mathrm{m}$, ACQUITY UPLC HSS, Waters, Milford, MA, USA) was used at $40{ }^{\circ} \mathrm{C}$. The mobile phase consisted of (A) water and (B) acetonitrile, both containing $0.1 \%$ formic acid, and the gradient program was: $0 \mathrm{~min}, 5 \% \mathrm{~B} ; 7 \mathrm{~min}, 20 \% \mathrm{~B} ; 13 \mathrm{~min}, 50 \% \mathrm{~B} ; 14.5 \mathrm{~min}, 100 \% \mathrm{~B} ; 17 \mathrm{~min}$, $100 \% \mathrm{~B}$. The flow rate was $0.35 \mathrm{~mL} / \mathrm{min}$, and the injection volume was $2 \mu \mathrm{L}$. The source parameters were as follows: dry gas $\left(\mathrm{N}_{2}\right)$ temperature $350{ }^{\circ} \mathrm{C}$; flowrate $8 \mathrm{~L} / \mathrm{min}$; sheath gas flow $8 \mathrm{~L} / \mathrm{min}$ with heater at $350{ }^{\circ} \mathrm{C}$; nebulizer pressure, $45 \mathrm{psi}$; capillary voltage $3500 \mathrm{~V}$, and dwell time of each ion pair $20 \mathrm{~ms}$. (2) a UPLC C18 analytical column $(2.1 \mathrm{~mm} \times 100 \mathrm{~mm}$, I.D. $1.7 \mu \mathrm{m}, \mathrm{BEH})$ coupled with a C18 pre-column $(2.1 \mathrm{~mm} \times 5 \mathrm{~mm}$, I.D.1.7 $\mu \mathrm{m}$, ACQUITY UPLC BEH, Waters, USA) was used for chromatographic separations at $60{ }^{\circ} \mathrm{C}$. The mobile phase consisted of $3 \mathrm{mM}$ ammonium acetate in water (A) and methanol (B), and the gradient program was: $0 \mathrm{~min}, 35 \% \mathrm{~B} ; 7 \mathrm{~min}, 100 \% \mathrm{~B} ; 7-9 \mathrm{~min}, 100 \%$ B. The flow rate was $0.35 \mathrm{~mL} / \mathrm{min}$; the injection volume was $2 \mu \mathrm{L}$. The mass spectrometer parameters were set as: dry gas $\left(\mathrm{N}_{2}\right)$ temperature $300{ }^{\circ} \mathrm{C}$; flow rate $7 \mathrm{~L} / \mathrm{min}$; sheath gas flow $8 \mathrm{~L} / \mathrm{min}$; sheath gas heater $350{ }^{\circ} \mathrm{C}$; nebulizer pressure, $45 \mathrm{psi}$; $500 \mathrm{~V}$ charging; capillary voltage $3500 \mathrm{~V}$; and the dwell time for each ion pair was $40 \mathrm{~ms}$. Other details are shown in Table 1. Each sample was analyzed in triplicate, and the final chemical contents of each analyte were calculated as an average \pm standard deviation (SD) of those three readings.

\subsubsection{Quantitative Method Validation}

Method validation in terms of linearity, LODs, LOQs, precision (intra-day and inter-day), repeatability, recovery and stability was carried out. The stock solutions of reference standards were diluted with methanol to yield a series of appropriate concentration solutions for assessing linearity, LODs (signal-to-noise $(S / N)$ ratios of 3) and LOQs ( $S / N$ ratios of 10 ).

The precision validation of the assay method was calculated based on intra-day and inter-day variations. For intra-day variation assessment, six replicates of the PMR-RMA5 and micro-dissected tissues PMR-TC4-5 and PMR-TC7-6 were extracted and analyzed over the course of one day. For the inter-day variability test, the same samples were examined in triplicate on two consecutive days. Variations were expressed by the RSDs of the data $(n=6)$.

Method repeatability was evaluated by assessing variation in six replicated extracts of PMR-RMA5, PMR-TC2-5 and PMR-TC3-6. A stability test was performed on the sample solutions of PMR-RMA5, PMR-TC2-5 and PMR-TC3-6 over periods of 0, 2, 4, 8, 12, 24, $48 \mathrm{~h}$ after extraction, respectively.

As a recovery test for raw materials, $0.1 \mathrm{~g}$ of PMR-RMA5 was accurately weighed and different amounts (low, middle and high levels) of reference standards (gallic acid: 14.00, 18.00 and $22.00 \mu \mathrm{g}$; proanthocyanidin B1: 38.00, 48.00 and 57.00 $\mu$ g; proanthocyanidin B2: $13.00,16.00$ and $19.00 \mu \mathrm{g}$; catechin: 130.00, 160.00 and $190.00 \mu \mathrm{g}$; epicatechin: 8.00, 10.00 and $12.00 \mu \mathrm{g}$; epicatechin-3-gallate: 
18.00, 23.00 and 28.00 $\mu \mathrm{g}$; cis-THSG:, and 32.00, 40.00, 48.00 $\mathrm{gg}$; trans-THSG: 3.08, 3.85 and $4.62 \mathrm{mg}$; emodin-8-O- $\beta$-D-glucoside: $125.00,156.00$ and $187.00 \mu$; physcion-8-O- $\beta$-D-glucoside: $19.00,24.00$ and $29.00 \mu \mathrm{g}$; emodin: 30.00, 38.00 and $46.00 \mu \mathrm{g}$; physcion: 25.00, 32.00 and $38.00 \mu \mathrm{g}$, repectively) were spiked, and then extracted and analyzed in triplicate.

To assess the recovery for micro-dissected tissues, tissues with known contents of the 12 analytes were cut by LMD with an area of $1.5 \times 10^{6} \mu^{2}$, and different amounts (low, middle and high levels) of reference standards (gallic acid: 90, 110 and $130 \mathrm{ng}$; proanthocyanidin B1: 40, 50 and $60 \mathrm{ng}$; proanthocyanidin B2: 110, 140 and $170 \mathrm{ng}$; catechin: 200, 250 and $300 \mathrm{ng}$; epicatechin: 100, 125 and 150 ng; epicatechin-3-gallate: 120, 150 and 180 ng; cis-THSG: 2300, 2800 and 3300 ng; trans-THSG: 3600, 4400 and 5200 ng; emodin-8-O- $\beta$-D-glucoside: 150, 190 and 230 ng; physcion-8-O- $\beta$-D-glucoside: 22 , 27 and 32 ng; emodin: 150, 180 and 210 ng; physcion: 80, 100 and 120 ng, in solution, respectively) were spiked, then extracted and analyzed in triplicate for each level.

\subsection{Data Analysis}

The quantitative data obtained were processed by Agilent Mass Hunter Work station software-Quantitative Analysis (version B.06.00, Build 6.0.388.1, Agilent Technologies Inc., Santa Clara, CA, USA, 2008). Data were presented as mean \pm SD of triplicate determinations. To compare the significant differences between the content of active compounds in the samples, one-way ANOVA was conducted by IBM SPSS Statistics 19.0 software (IBM, USA). A significant difference is indicated by $p$ values.

\section{Conclusions}

In this study, a combination of LMD and UHPLC-QqQ-MS/MS was applied for histochemical analysis of different commercial grades of PMR, both raw material and individual tissues, in order to find the scientific basis for grading classification. UHPLC-QqQ-MS/MS was used to determine quantitatively the content of 12 major bioactive components of PMR raw materials firstly, and then LMD coupled with UHPLC-QqQ-MS/MS was used to determine and find the distribution patterns of three major types of chemicals (12 analytes) in different tissues of PMR. Results indicated that traditional commercial grades based on size and weight of PRM did not correspond to any significant difference in chemical content. Interestingly, the tissue-specific analysis revealed a strong and consistent relationship between phytochemicals and histologic structures. In particular, stilbene glucosides, combined anthraquinones and polyphenols, were mainly distributed in the cork, and free anthraquinones were mainly distributed in the phloem. Thus, PMR with broader cork and phloem, as seen in a transverse section, were typically of better quality as these parts are where the bioactive components accumulated. The tissue-specific analysis of secondary metabolites creates a reliable morphological criterion for the quality grading of PMR.

Supplementary Materials: Table S1: Method optimization for quantification of secondary metabolites Table S2: Quantitative results of secondary metabolites in raw materials of PMR $\left(\mu \mathrm{g} \cdot \mathrm{g}^{-1}\right)(n=3)$. Table S3: Quantitative results of secondary metabolites in micro-dissected tissues of PMR (ng/106 $\left.\mu \mathrm{m}^{2}\right)(n=3)$.

Author Contributions: The list of authors who contributed to this work is as follows: L.L., J.X. and Z.-T.L. conceived and designed the experiment; L.L. performed the experiment and analyzed the data; Z.-T.L., X.-P.D., H.-B.C. and Z.-Z.Z. guided the experiment; L.L. wrote the paper; J.X. revised the paper; Z.-Z.Z. acquired funding for the research. All authors read and approved the final manuscript.

Acknowledgments: We acknowledge Shenzhen Tsumura Medicine Co., Ltd. for providing us sample materials. We thank Alan Ho from the School of Chinese Medicine, Hong Kong Baptist University, for his technical assistance. This work was supported by Research Grants Council (Project No. 12102415) and National Natural Science Foundation of the People's Republic of China (Project No. 11475248).

Conflicts of Interest: All authors declare there is no conflict of interest. 


\section{References}

1. Zhao, Z.Z.; Liang, Z.T.; Guo, P. Macroscopic Identification of Chinese Medicinal Materials: Traditional Experiences and Modern Understanding. J. Ethnopharmacol. 2011, 134, 556-564. [CrossRef] [PubMed]

2. Chu, X.H.; Wang, J.B.; Zhou, C.P.; Xia, X.H.; Zhang, P.; Xiao, X.H.; Yuan, H.L.; Zhao, H.P.; Zhang, X.R. Comparison of Antioxidative Activities of Fructus Lycii with Different Commercial Grades by Bioassay Detection. Chin. J. New Drugs 2011, 20, 599-603.

3. Wang, J.B.; Zhang, X.R.; Xiao, X.H.; Chu, X.H.; Zhou, C.P.; Jin, C.; Yan, D. Rationality of Commercial Specification of Rhubarb Based on Chemical Analysis. Zhongguo Zhong Yao Za Zhi 2010, 35, 470-476. [PubMed]

4. Al-Saidi, S.; Rameshkumar, K.B.; Hisham, A.; Sivakumar, N.; Al-Kindy, S. Composition and Antibacterial Activity of the Essential Oils of Four Commercial Grades of Omani Luban, the Oleo-Gum Resin of Boswellia Sacra Flueck. Chem. Biodivers. 2012, 9, 615-624. [CrossRef] [PubMed]

5. Wang, Z.H.; Wang, D.M.; Huang, L.F. Analysis of the Correlation between Commodity Grade and Quality of Angelica Sinensis by Determination of Active Compounds Using Ultraperformance Liquid Chromatography Coupled with Chemometrics. Evid.-Based Complement. Altern. Med. 2014, 2014. [CrossRef] [PubMed]

6. Wang, Z.H.; Jin, L.; Ma, Y.; Cui, Z.; Li, Q.; Huang, D.D. NAnalysis of Commercial Grades of Schisandrae Sphenantherae Fructus Based on Schisantherin. Zhongguo Zhong Yao Za Zhi 2017, 42, 3728-2732. [PubMed]

7. Ng, K.M.; Liang, Z.T.; Lu, W.; Tang, H.W.; Zhao, Z.Z.; Che, C.M.; Cheng, Y.C. In Vivo Analysis and Spatial Profiling of Phytochemicals in Herbal Tissue by Matrix-Assisted Laser Desorption/Ionization Mass Spectrometry. Anal. Chem. 2007, 79, 2745-2755. [CrossRef] [PubMed]

8. Wu, W.; Qiao, C.F.; Liang, Z.T.; Xu, H.X.; Zhao, Z.Z.; Cai, Z.W. Alkaloid Profiling in Crude and Processed Strychnos Nux-Vomica Seeds by Matrix-Assisted Laser Desorption/ionization-Time of Flight Mass Spectrometry. J. Pharm. Biomed. Anal. 2007, 45, 430-436. [CrossRef] [PubMed]

9. Wu, W.; Liang, Z.T.; Zhao, Z.Z.; Cai, Z.W. Direct Analysis of Alkaloid Profiling in Plant Tissue by Using Matrix-Assisted Laser Desorption/ionization Mass Spectrometry. J. Mass Spectrom. 2007, 42, 58-69. [CrossRef] [PubMed]

10. Yi, L.; Liang, Z.T.; Peng, Y.; Yao, X.; Chen, H.B.; Zhao, Z.Z. Tissue-Specific Metabolite Profiling of Alkaloids in Sinomenii Caulis Using Laser Microdissection and Liquid Chromatography-Quadrupole/time of Flight-Mass Spectrometry. J. Chromatogr. A 2012, 1248, 93-103. [CrossRef] [PubMed]

11. Liang, Z.T.; Sham, T.; Yang, G.Y.; Yi, L.; Chen, H.B.; Zhao, Z.Z. Profiling of Secondary Metabolites in Tissues from Rheum Palmatum L. Using Laser Microdissection and Liquid Chromatography Mass Spectrometry. Anal. Bioanal. Chem. 2013, 405, 4199-4212. [CrossRef] [PubMed]

12. Wang, Q.L.; Liang, Z.T.; Peng, Y.; Hou, J.L.; Wei, S.L.; Zhao, Z.Z.; Wang, W.Q. Whole Transverse Section and Specific-Tissue Analysis of Secondary Metabolites in Seven Different Grades of Root of Paeonia Lactiflora Using Laser Microdissection and Liquid Chromatography-Quadrupole/time of Flight-Mass Spectrometry. J. Pharm. Biomed. Anal. 2015, 103, 7-16. [CrossRef] [PubMed]

13. Krauss, M.; Singer, H.; Hollender, J. LC-High Resolution MS in Environmental Analysis: From Target Screening to the Identification of Unknowns. Anal. Bioanal. Chem. 2010, 397, 943-951. [CrossRef] [PubMed]

14. Anderson, L.; Hunter, C.L. Quantitative Mass Spectrometric Multiple Reaction Monitoring Assays for Major Plasma Proteins. Mol. Cell. Proteom. 2006, 5, 573-588. [CrossRef] [PubMed]

15. Engström, M.T.; Pälijärvi, M.; Salminen, J.P. Rapid Fingerprint Analysis of Plant Extracts for Ellagitannins, Gallic Acid, and Quinic Acid Derivatives and Quercetin-, Kaempferol- and Myricetin-Based Flavonol Glycosides by UPLC-QqQ-MS/MS. J. Agric. Food Chem. 2015, 63, 4068-4079. [CrossRef] [PubMed]

16. Guo, B.; Chen, B.; Liu, A.; Zhu, W.; Yao, S. Liquid Chromatography-Mass Spectrometric Multiple Reaction Monitoring-Based Strategies for Expanding Targeted Profiling towards Quantitative Metabolomics. Curr. Drug Metab. 2012, 13, 1226-1243. [CrossRef] [PubMed]

17. Peterson, A.C.; Russell, J.D.; Bailey, D.J.; Westphall, M.S.; Coon, J.J. Parallel Reaction Monitoring for High Resolution and High Mass Accuracy Quantitative, Targeted Proteomics. Mol. Cell. Proteom. 2012, 11, 1475-1488. [CrossRef] [PubMed]

18. Outlaw, W.H.; Zhang, S. Single-Cell Dissection and Microdroplet Chemistry. J. Exp. Bot. 2001, 52, 605-614. [CrossRef] [PubMed] 
19. Moco, S.; Schneider, B.; Vervoort, J. Plant Micrometabolomics: The Analysis of Endogenous Metabolites Present in a Plant Cell or Tissue. J. Proteome Res. 2009, 8, 1694-1703. [CrossRef] [PubMed]

20. Fricker, M.; Runions, J.; Moore, I. Quantitative Fluorescence Microscopy: From Art to Science. Annu. Rev. Plant Biol. 2006, 57, 79-107. [CrossRef] [PubMed]

21. Chen, Y.J.; Liang, Z.T.; Zhu, Y.; Xie, G.Y.; Tian, M.; Zhao, Z.Z.; Qin, M.J. Tissue-Specific Metabolites Profiling and Quantitative Analyses of Flavonoids in the Rhizome of Belamcanda Chinensis by Combining Laser-Microdissection with UHPLC-Q/TOF-MS and UHPLC-QqQ-MS. Talanta 2014, 130, 585-597. [CrossRef] [PubMed]

22. Chinese Pharmacopoeia Commission. Pharmacopoeia of People's Republic of China, Version 2015; China Medical Science Publisher: Beijing, China, 2015; Volume 1.

23. Lin, L.; Ni, B.; Lin, H.; Zhang, M.; Li, X.; Yin, X.; Qu, C.; Ni, J. Traditional Usages, Botany, Phytochemistry, Pharmacology and Toxicology of Polygonum Multiflorum Thunb.: A Review. J. Ethnopharmacol. 2015, 159, 158-183. [CrossRef] [PubMed]

24. Li, S.Z. Compendium of Materia Medica (Ben Cao Gang Mu); Shanghai Science and Technology Publisher: Shanghai, China, 2008.

25. Bai, S.Q.; Zhang, X.Q. Chinese Material Medica Commoditology; Tianjin Science and Technology Press: Tianjin, China, 1999.

26. Liang, Z.T.; Shi, Y.X.; Chen, H.B.; Zhao, Z.Z. Histochemical Analysis of the Root Tuber of Polygonum Multiflorum Thunb. (Fam. Polygonaceae). Microsc. Res. Tech. 2011, 74, 488-495. [CrossRef] [PubMed]

27. Kim, H.K.; Choi, Y.H.; Choi, J.S.; Choi, S.U.; Kim, Y.S.; Lee, K.R.; Kim, Y.K.; Ryu, S.Y. A New Stilbene Glucoside Gallate from the Roots of Polygonum Multiflorum. Arch. Pharm. Res. 2008, 31, 1225-1229. [CrossRef] [PubMed]

28. Choi, S.G.; Kim, J.; Sung, N.D.; Son, K.H.; Cheon, H.G.; Kim, K.R.; Kwon, B.M. Anthraquinones, Cdc25B Phosphatase Inhibitors, Isolated from the Roots of Polygonum Multiflorum Thunb. Nat. Prod. Res. 2007, 21, 487-493. [CrossRef] [PubMed]

29. Han, D.Q.; Zhao, J.; Xu, J.; Peng, H.S.; Chen, X.J.; Li, S.P. Quality Evaluation of Polygonum Multiflorum in China Based on HPLC Analysis of Hydrophilic Bioactive Compounds and Chemometrics. J. Pharm. Biomed. Anal. 2013, 72, 223-230. [CrossRef] [PubMed]

Sample Availability: Samples of the trans-2,3,5,4'-tetrahydroxystilbene-2-O- $\beta$-D-glucopyranoside (trans-THSG), cis-THSG, emodin, physcion, emodin- $8-O-\beta$-D-glucosides and physcion- $8-O-\beta$-D-glucosides, gallic acid, proanthocyanidin B1, proanthocyanidin B2, epicatechin, catechin and epicatechin-3-gallate are available from the authors.

(C) 2018 by the authors. Licensee MDPI, Basel, Switzerland. This article is an open access article distributed under the terms and conditions of the Creative Commons Attribution (CC BY) license (http://creativecommons.org/licenses/by/4.0/). 